\title{
Ecosystem metabolism in a temporary Mediterranean marsh (Doñana National Park, SW Spain)
}

\author{
O. Geertz-Hansen ${ }^{1, *}$, C. Montes ${ }^{2}$, C. M. Duarte ${ }^{3,4}$, K. Sand-Jensen ${ }^{1}$, N. Marbá ${ }^{3}$, and P. Grillas ${ }^{5}$ \\ ${ }^{1}$ Freshwater Biological Laboratory, University of Copenhagen, 51 Helsingørsgrade, 3400 Hillerød, Denmark \\ ${ }^{2}$ Departamento de Ecología, Universidad Autónoma, 28049 Madrid, Spain \\ ${ }^{3}$ IMEDEA (CSIC-UIB), Grupo de Oceanografía Interdisciplinar, Instituto Mediterráneo de Estudios Avanzados, C/Miquel \\ Marqués, 21, 07190 Esporles, Illes Balears, Spain \\ ${ }^{4}$ UWA Oceans Institute, University of Western Australia, 35 Stirling Highway, Crawley 6009, Australia \\ ${ }^{5}$ Station Biologique de la Tour du Valat, 13200 Le Sambuc, France \\ * present address: AquaSim, Slagslunde Bygade 37, 3660 Stenløse, Denmark
}

Received: 22 June 2010 - Published in Biogeosciences Discuss.: 26 August 2010

Revised: 7 March 2011 - Accepted: 7 March 2011 - Published: 19 April 2011

\begin{abstract}
The metabolic balance of the open waters supporting submerged macrophytes of the Doñana marsh (SW Spain) was investigated in spring, when community production is highest. The marsh community (benthic + pelagic) was net autotrophic with net community production rates averaging $0.61 \mathrm{~g} \mathrm{C} \mathrm{m}^{-2} \mathrm{~d}^{-1}$, and gross production rates exceeding community respiration rates by, on average, $43 \%$. Net community production increased greatly with increasing irradiance, with the threshold irradiance for communities to become net autotrophic ranging from 42 to $255 \mu \mathrm{E} \mathrm{m}^{-2} \mathrm{~s}^{-1}$, with net heterotrophic at lower irradiance. Examination of the contributions of the benthic and the pelagic compartments showed the pelagic compartment to be strongly heterotrophic (average $P / R$ ratio $=0.27$ ), indicating that the metabolism of the pelagic compartment is highly subsidised by excess organic carbon produced in the strongly autotrophic benthic compartment (average $P / R=1.58$ ).
\end{abstract}

\section{Introduction}

Freshwater and brackish marshes with temporary shallow lagoons are key ecosystems in the Mediterranean landscape, playing a regulatory role in the hydrological cycle (groundwater recharge and discharge, flood control), retaining sediments, pollutants and nutrients, and acting as important refuge for breeding wildlife and as feeding grounds on the

Correspondence to: C. M. Duarte (carlosduarte@imedea.uib.es) main migratory routes of European birds (Hollis and Jones, 1991; Barnes, 1991; Skinner and Zalewski, 1995). These ecosystems also provide important goods and services to society, such as hunting, fisheries, pastures for livestock grazing, tourism and recreation (Skinner and Zalewski, 1995; Grillas et al., 2004). The high animal biomass supported by Mediterranean wetlands implies high production (van Vierssen, 1982).

Primary producers in shallow $(<1 \mathrm{~m})$ Mediterranean marshes, including Doñana, comprise mostly emergent helophytes and submerged macrophytes (Characeae, Ruppiaceae, Zannicheliaceae Van Vierssen, 1982; Grillas, 1990; Grillas and Roché, 1997; Grillas et al., 2004; Duarte et al., 1990; Garcia Murillo et al., 1993), as well as, poorly documented, planktonic and benthic microalgae. While the importance of emergent macrophytes as primary producers has been evaluated in freshwater marshes in the past (Keddy, 2000; Mitsh and Gosselink, 2000) the contribution of submerged macrophytes, phytoplankton, and benthic microalgae remains mostly unknown. Yet, the shallow lagoons in Mediterranean wetlands have the potential to support highly productive communities of each of these components. Because they also support very high biomasses of heterotrophic organisms, respiratory demands are likely to be very high. Consequently, heterotrophic demands may exceed authochthonous primary production, requiring allochthonous inputs of organic matter to support the excess heterotrophy. Yet, there is again a remarkable paucity of information on the metabolic balance of Mediterranean wetlands (see LópezArchilla et al., 2004). 
Aquatic metabolism is a transient feature of Mediterranean wetlands, which are characterised by a dry phase extending from the summer to the late fall, and a flooded phase from winter to early summer. Aquatic macrophytes reach their maximum biomass and activity in Mediterranean wetlands in spring, when community production is highest (LópezArchilla et al., 2004) and consumer abundance (invertebrates, birds, etc.) peaks. The metabolic balance at this particular period in the seasonal development of Mediterranean marshes is particularly important in terms of assessing whether authocthonous primary production suffices to satisfy heterotrophic carbon demands.

The simultaneous evaluation of both community primary production and respiration of the communities is essential to elucidate the metabolic balance of the communities and their status as autotrophic or heterotrophic systems. If autotrophic, the system produces organic carbon in excess of local demands and will therefore export or accumulate organic carbon. On the contrary, if heterotrophic, the ecosystem will be dependent on allochthonous inputs, creating links with adjacent ecosystems (Odum and Barret, 2005). Heterotrophic aquatic ecosystems have been recently argued to be far more prevalent than believed in the past (Duarte and Prairie, 2005). A net heterotrophic metabolism is most likely in unproductive ecosystems, whereas highly productive ones, such as Mediterranean marshes,tend to be net autotrophic (Duarte and Agustí, 1998).

Our goal was to evaluate the metabolic balance (gross primary production, community respiration and net community production) and the relative contribution of submerged macrophytes, phytoplankton, and benthic microalgae as primary producers in the Doñana marsh (SW Spain), the largest marsh in the Mediterranean region (Britton and Crivelli, 1993). We achieved this goal by measuring the daily oxygen balance of the open waters in nine temporary zones supporting different aquatic communities across the marsh, and elucidating the contributions of submerged macrophytes, and their associated epiphytes, phytoplankton and benthic microalgae. Measurements were conducted in spring when both primary producers and consumers reach their maximum abundance.

\section{Study area}

The Doñana marshes are comprised of shallow $(<1 \mathrm{~m})$, temporary water bodies covering $298 \mathrm{~km}^{2}$ of the $553 \mathrm{~km}^{2}$ of the Doñana National Park (SW Spain). The marshes constitute one of the most important breeding localities for European waterfowl, supporting dense populations that include many endangered species (Amat, 1981). The climate of the area is predominantly Mediterranean, with Atlantic influence and average rainfall of $580 \mathrm{~mm}$, with most precipitation occurring in autumn and spring. Winters are mild with an average daily temperature of $9.3^{\circ} \mathrm{C}$ while summers are very dry with temperatures reaching up to $30^{\circ} \mathrm{C}$ in July and August. The marsh experiences annual, though highly variable, cycles of flooding (November to March) and subsequent desiccation (May to June) to become fully dried during midsummer. Dependence on rainfall makes inundation cycles highly unpredictable, as rainfall distribution shows an important interannual variability affecting the relative duration of the dry and flooded phases. During extreme drought periods most of the marsh remains dry, and macrophyte development is precluded. There is also important spatial variability in the wetlands across the $298 \mathrm{~km}^{2}$ of the Doñana National Park marshes, involving in particular a salinity gradient, with the NW sector showing the lowest salinity and the SE sector showing the highest salinity. This gradient reflects the NE source of freshwater and the higher salinity in the sediments at the SE sector ((Bernues,1990; Santamaria et al., 1996). This gradient imposes variability in macrophyte community structure (Duarte et al., 1990). Vegetation communities in the marshes include emergent, floating-leaved and submerged macrophytes (Rivas Martinez et al., 1980; Garcia et al., 1993; Espinar et al., 2002).

During particularly dry years, the marsh remains dry, precluding macrophyte development. Water is turbid and nutrient-rich at the time of flooding (Bernués, 1990, Santamaria et al., 1996), to the extent that macrophyte development is precluded by the insufficient light reaching to the sediments during extreme flood periods. Transparency increases subsequently by settling of suspended particles, and nutrients are depleted in the waters during macrophyte growth (Bernués, 1990). Submerged macrophytes colonize from the abundant seed banks (Grillas et al., 1993) in early spring (March-April) and form dense meadows to reach peak biomass shortly after in late April -May, parallel to evaporation and increasing salt concentration in the lagoon water (mostly NaCl, conductivity 1-70 mS; Bernués, 1990). Thus, peak primary production occurs at a time when the lagoons are shallow $(<60 \mathrm{~cm})$ and depleted in dissolved nutrients (Santamaria et al., 1996).

This study examined the community metabolism of the areas dominated by submerged macrophytes. Nine study sites were established along the marsh to encompass the widest possible range in depth, indicative of the hydrological regime, and macrophyte abundance and species composition, thereby acquiring knowledge on the range of metabolic rates and the relative contribution by different plant components. Seven of the sites were located in the brackish eastern sector of the marsh, and two of the stations located in the western freshwater sector (Fig. 1). Macrophyte biomass and community metabolism were assessed at these stations in April 1991 (11 to 21 April), at the time of peak macrophyte biomass. The 1990-1991 hydrological cycle was characterised by an average extent of flooding, allowing optimal macrophyte development (Coleto, 2004). The Doñana marsh experienced a dry period after the completion of this study and returned to a wet period in the 1995-1996 hydrological cycle, with dry 
Table 1. Water depth, phytoplankton and macrophyte biomass, temperature range and daily irradiance (PAR) during the diel $\mathrm{O}_{2}$ experiments in nine shallow Doñana lagoons. Dominant species are macrophyte species comprising more than $20 \%$ of the biomass. Chara $=$ Chara sp-, Ruppia = Ruppia drepanensis, Myrio. = Myriophyllum spicatum, Ranunc. $=$ Ranunculus baudotii, Zann. = Zannichellia obstusifolia .

\begin{tabular}{|c|c|c|c|c|c|c|c|}
\hline Station & Name & $\begin{array}{l}\text { Depth } \\
(\mathrm{m})\end{array}$ & $\begin{array}{c}T \text { range } \\
\left({ }^{\circ} \mathrm{C}\right)\end{array}$ & $\begin{array}{l}\text { Surface irradiance } \\
\qquad\left(\mathrm{E} \mathrm{m}^{-2} \mathrm{~d}^{-1}\right)\end{array}$ & $\begin{array}{l}\text { Phytopl. Biomass } \\
\qquad\left(\mathrm{g} \mathrm{C} \mathrm{m}^{-2}\right)\end{array}$ & $\begin{array}{l}\text { Macrophyte biomass } \\
\qquad\left(\mathrm{g} \mathrm{C} \mathrm{m}^{-2}\right)\end{array}$ & Dominant species \\
\hline 1 & C. Travieso & 0.42 & $19-25$ & 47 & 0.029 & 2 & Chara \\
\hline 2 & L. Veta Alta & 0.30 & $14-22$ & 53 & 0.019 & 5.8 & Ruppia, Chara \\
\hline 3 & L. Mari López & 0.25 & $15-24$ & 50 & 0.016 & 10.5 & Chara, Ruppia \\
\hline 4 & L. Palacio & 0.18 & $12-19$ & 29 & 0.021 & 41.7 & Myrio., Ranunc. \\
\hline 5 & L. Caballero & 0.24 & $15-23$ & 37 & 0.015 & 20.9 & Ruppia, Zann. \\
\hline 6 & L. Ansares (W) & 0.25 & $17-27$ & 48 & 0.041 & 7.4 & Chara \\
\hline 7 & C. Carratoja & 0.60 & $17-25$ & 48 & 0.032 & 48.1 & Zann., Chara \\
\hline 8 & L. Buen Tiro & 0.21 & $16-24$ & 37 & 0.007 & 3.6 & Ruppia, Chara \\
\hline 9 & L. Ansares (E) & 0.32 & $16-22$ & 38 & 0.009 & 37.4 & Ruppia \\
\hline Mean & & 0.30 & 18.9 & 43 & 0.017 & 12.1 & \\
\hline
\end{tabular}

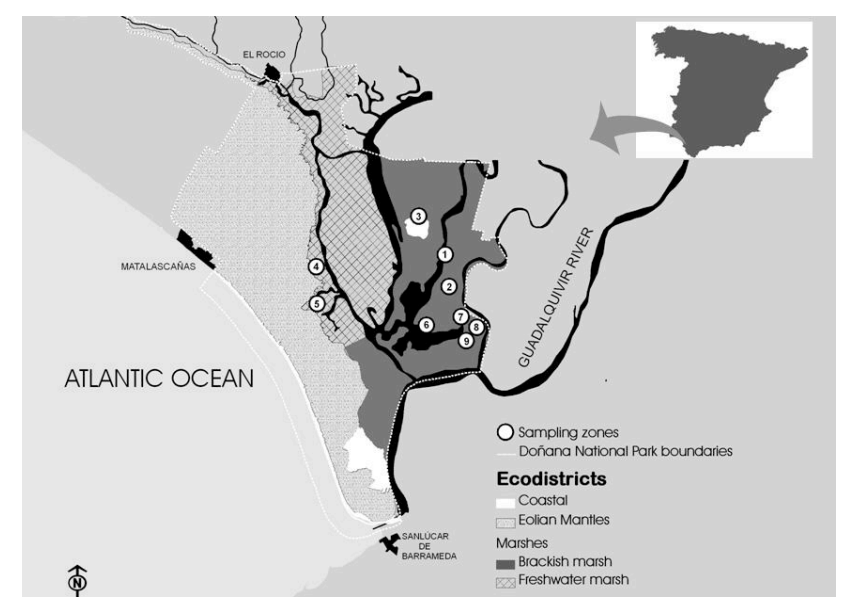

Fig. 1. Map of the study area showing the location of the study sites and the major ecological districts in the Doñana Park, SW Spain.

years, when the marsh is not fully flooded and macrophyte cover in the spring is limited in 1998-1999 and 2004-2005.

\section{Materials and methods}

Macrophyte biomass was calculated at each station, from three random core samples taken using a $15 \mathrm{~cm}$ diameter internal diameter corer. The plants were sorted to species, dried overnight at $105^{\circ} \mathrm{C}$ and weighed. Carbon content of the different species was measured on a Carlo Erba CHN-analyzer, allowing calculation of the total macrophyte carbon biomass per square meter. $\mathrm{pH}$ and conductivity were measured in situ using calibrated $\mathrm{WTW}^{\mathrm{tm}} \mathrm{pH}$ and conductivity meters.

Phytoplankton and microphytobenthos biomasses were calculated from chlorophyll-a measurements, assuming a carbon to chlorophyll ratio of 50 (Lorenzen, 1968). For de- termination of phytoplankton chlorophyll-a, duplicate 300$900 \mathrm{ml}$ samples were filtered onto $25 \mathrm{~mm}$ GF/C filters, extracted overnight in $5 \mathrm{ml}$ of $96 \%$ ethanol and analyzed according to Jespersen and Christoffersen (1987). In order to assess the microphytobenthos biomass, the uppermost $0.5 \mathrm{~cm}$ of each of five replicated $3.8 \mathrm{~cm}^{2}$ sediment cores per station was extracted in $25 \mathrm{ml}$ ethanol and chlorophyll a was subsequently determined as indicated above.

The metabolic balance of the communities at the nine sampling stations was examined following the oxygen balance during one full diel period at each site. Pelagic primary production and respiration were measured by the oxygen light/dark bottle technique using Winkler titration. We used triplicate $125 \mathrm{ml} \mathrm{BOD}$ bottles suspended in the mid depth of the water column for $24 \mathrm{~h}$. Respiration $(\mathrm{R})$ was calculated from the difference in oxygen concentration before and after incubation in dark bottles, net community production (NCP) from the change in oxygen concentration in light bottles, and gross production (GP) was calculated as R+NCP. Oxygen values were converted to carbon units using a molar ratio of $\mathrm{O}_{2}$ to $\mathrm{CO}_{2}$ of 1.2 (Langdon, 1988), thereby allowing comparison with plant biomass in carbon units. Depth-integrated values were calculated by assuming that the mid-depth incubations were representative of the entire water column. This assumption is reasonable because of the shallow water column (18- $60 \mathrm{~cm}$, Table 1$)$ and the low light extinction coefficient $\left(0.3-1.6 \mathrm{~m}^{-1}\right)$ of the waters.

Whole-system metabolism was calculated from diurnal measurements of oxygen, temperature, irradiance, and wind speed by a setup consisting of an oxygen electrode with stirrer and thermistor (Syland 4000), one quantum sensor in air and one submerged (LI-COR) to the upper level of submerged vegetation, and a cup anemometer (Thies Clima). All sensors run on batteries and were connected to a datalogger (LI-COR, LI-1000) recording data at $5 \mathrm{~s}$ intervals. The data were averaged over $30 \mathrm{~min}$ intervals to filter out noise due, 
for instance, to cloud passage. Calculations of whole system oxygen metabolism followed principles of Odum and Hoskin (1958) and Odum and Wilson (1962). For every $30 \mathrm{~min}$ net oxygen production $\left(\mathrm{NCP}_{\text {period }}, \mathrm{g} \mathrm{O}_{2} \mathrm{~m}^{-2}\right.$ ) was calculated as:

$\mathrm{NCP}_{\text {period }}=\left(C_{n+1}-C_{n}\right) d+F(t)$

where $C_{n}$ and $C_{n+1}$ are oxygen concentrations $\left(\mathrm{g} \mathrm{O}_{2} \mathrm{~m}^{-3}\right)$ over two successive sampling intervals, $d$ is water depth (m), $F$ is the calculated oxygen flux from the water to the atmosphere $\left(\mathrm{g} \mathrm{O}_{2} \mathrm{~m}^{-2} \mathrm{~h}^{-1}\right)$, and $t$ is the incubation time (h). Daily net production ( $\mathrm{NCP}, \mathrm{g} \mathrm{O}_{2} \mathrm{~m}^{-2} \mathrm{~d}^{-1}$ ), was then calculated as the sum of 48 successive half-hour periods.

Daily respiration $\left(R, \mathrm{~g} \mathrm{O}_{2} \mathrm{~m}^{-2} \mathrm{~d}^{-1}\right.$ ) was calculated from the decline in oxygen during the night, resulting in negative estimates of net production during the night $\left(\mathrm{NCP}_{\mathrm{N}}\right)$ as,

$$
R=-\mathrm{NCP}_{\mathrm{N}} t_{\mathrm{N}}^{-1} 24
$$

where $t_{\mathrm{N}}$ is the duration of the night calculated from the number of periods with surface irradiance $<1 \mu \mathrm{E} \mathrm{m}^{-2} \mathrm{~s}^{-1}$. Respiration is a temperature sensitive process and the lagoons show large diel temperature fluctuations. Calculation of daily respiration from values obtained during the night is nevertheless reasonable, because the temperature amplitude during the night is usually the same as during the day, and the mean temperature during night and day did not usually differ by more than one degree Celsius. Daily gross production (GP) was calculated as the sum of respiration and net production.

The flux $(F)$ of oxygen across the surface from water to air was calculated as

$$
F=K_{2}\left(C_{a}-C_{\mathrm{s}}\right)
$$

where $C_{\mathrm{s}}$ is the saturation concentration of oxygen $\left(\mathrm{g} \mathrm{O}_{2}\right.$ $\mathrm{m}^{-3}$ ) at actual temperature and salinity, $C_{\mathrm{a}}$ is the actual measured concentration and $K_{2}$ is the reaeration coefficient (m $\mathrm{h}^{-1}$ ). The reaeration coefficient for oxygen across lake surfaces depends mainly on wind speed (Gromiec, 1989). The relationship between $K_{2}$ and wind speed was determined in an experimental setup consisting of an anemometer and a floating basin fitted with an oxygen electrode and a thermistor. The basin was made of thick oxygen-impermeable plastic material, with a diameter of $0.46 \mathrm{~m}$ and $35 \mathrm{~cm}$ deep, containing $56 \mathrm{~L}$ of oxygen-depleted water in contact with the atmosphere. The time course of the increase in oxygen concentration in the enclosed water column was measured and logged as described for the metabolic measurements and the air-water oxygen flux ( $F$, which in this case is negative) was calculated as,

$F=\left(C_{n}-C_{n+1}\right) V A^{-1} t^{-1}$

where $V$ is the water volume enclosed $\left(\mathrm{m}^{3}\right), A$ is the surface area $\left(\mathrm{m}^{2}\right)$ of the basin, and $t$ is the time period between successive sampling steps, and $C_{n}$ and $C_{n+1}$ are the oxygen concentrations in successive sampling steps. $K_{2}$ was derived

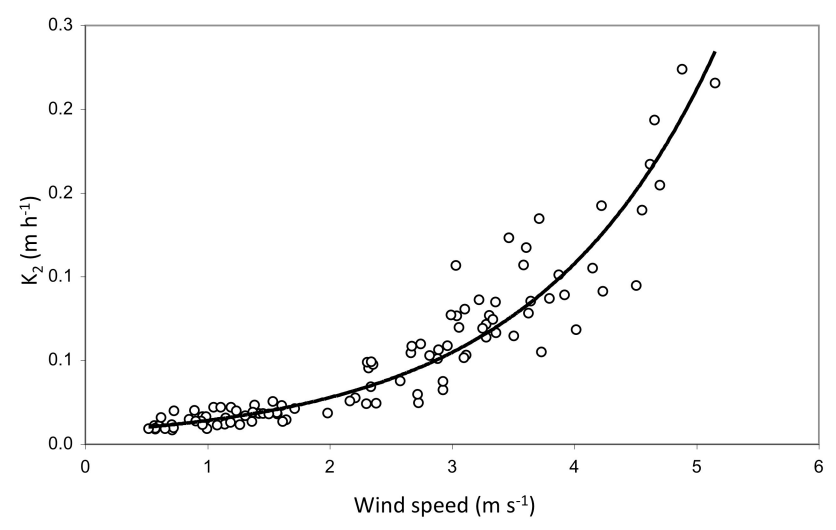

Fig. 2. The re-aeration coefficient for oxygen exchange between atmosphere and water as a function of wind speed.

by solving Eq. (3) and the resulting relationship between $K_{2}$ and wind speed $(N=104)$ was fitted by nonlinear regression to a power function of the form,

$K_{2}=a+b W^{C}$

where $a, b$, and $c$ are constants and $W$ is wind speed $\left(\mathrm{m} \mathrm{s}^{-1}\right)$, yielding the estimated parameters $\mathrm{a}=0.011 \mathrm{~m} \mathrm{~h}^{-1}$, $b=0.0027$ and $c=2.57$ for wind speeds between 0.5 and 5.0 $\mathrm{m} \mathrm{s}^{-1}$ with an $\mathrm{r}^{2}$ value of 0.92 (Fig. 2).

Benthic community metabolism was estimated as the difference between whole system and pelagic metabolism.

\section{Results and discussion}

The nine lagoons studied were all shallow $(0.18-0.60 \mathrm{~m})$ and differed considerably in submerged macrophyte biomass (2$48 \mathrm{~g} \mathrm{C} \mathrm{m}^{-2}$ ) and community structure (Table 1), encompassing the range of conditions encountered within the marsh (cf. Bernués, 1990; Duarte et al., 1990; Grillas et al., 1993). The waters had all high $\mathrm{pH}$ ( 8 to 10.3 , Table 1 ) and ranged threefold in conductivity ( 2500 to $6780 \mu \mathrm{S} \mathrm{cm}^{-1}$, Table 1 ).

Phytoplankton concentrations were consistently low ( $<3 \mathrm{mg}$ chlorophyll-a $\mathrm{m}^{-3}$, Table 1) yielding low phytoplankton biomass in the shallow water column $(0.006-$ $0.034 \mathrm{~g} \mathrm{C} \mathrm{m}^{-2}$, Table 1). Macrophyte biomass far exceeded phytoplankton biomass by 69-4200 fold. The chlorophyll content of benthic microalgae could not be quantified as it was below the detection limit of $1 \mathrm{mg}$ chlorophyll-a $\mathrm{m}^{-2}$.

Water temperature was up to $10^{\circ} \mathrm{C}$ higher in the evening than in the morning (Table 1). Oxygen concentration in the water column reached between 12 and $20 \mathrm{mg} \mathrm{O}_{2} \mathrm{~L}^{-1}$ during daytime in the different lagoons and it dropped to between 4 and $8 \mathrm{mg} \mathrm{O}_{2} \mathrm{~L}^{-1}$ during the night. The oxygen amplitude ranged from 35 to $240 \%$ of air saturation. Daily irradiance and temperature varied considerably during sampling, probably contributing to the measured variations in community metabolism among the different lagoons (Table 1). 
Table 2. Daily net community production (NCP), gross production (GP), and community respiration $(R)$ of the pelagic, benthic and entire communities in nine shallow Doñana lagoos, based on $24 \mathrm{~h} \mathrm{O}_{2}$ measurements. All rates in $\mathrm{g} \mathrm{C} \mathrm{m}^{-2} \mathrm{~d}^{-1}$.

\begin{tabular}{lllllllllll}
\hline Station & \multicolumn{3}{c}{ Pelagic } & \multicolumn{3}{c}{ Benthic } & \multicolumn{3}{c}{ Total } \\
\hline & NP & GP & $R$ & NP & GP & $R$ & NP & GP & $R$ \\
1 & -0.15 & 0.09 & 0.24 & 0.54 & 1.04 & 0.50 & 0.38 & 1.12 & 0.74 \\
2 & -0.06 & 0.04 & 0.09 & 1.23 & 1.96 & 0.73 & 1.17 & 2.00 & 0.82 \\
3 & -0.08 & 0.06 & 0.14 & 0.20 & 1.34 & 1.14 & 0.12 & 1.40 & 1.28 \\
4 & -0.12 & 0.01 & 0.14 & 0.17 & 2.26 & 2.08 & 0.05 & 2.27 & 2.22 \\
5 & -0.18 & 0.04 & 0.22 & 0.45 & 1.42 & 0.97 & 0.27 & 1.47 & 1.19 \\
6 & -0.12 & 0.10 & 0.22 & 0.28 & 1.08 & 0.80 & 0.16 & 1.18 & 1.02 \\
7 & & & & 1.23 & 4.69 & 3.47 & 1.09 & 4.74 & 3.65 \\
8 & -0.16 & 0.02 & 0.19 & 1.34 & 2.06 & 0.71 & 1.18 & 2.08 & 0.90 \\
9 & -0.22 & 0.02 & 0.24 & 1.31 & 1.95 & 0.64 & 1.09 & 1.98 & 0.89 \\
Mean & -0.14 & 0.05 & 0.18 & 0.73 & 1.98 & 1.25 & 0.61 & 2.03 & 1.41 \\
\hline
\end{tabular}

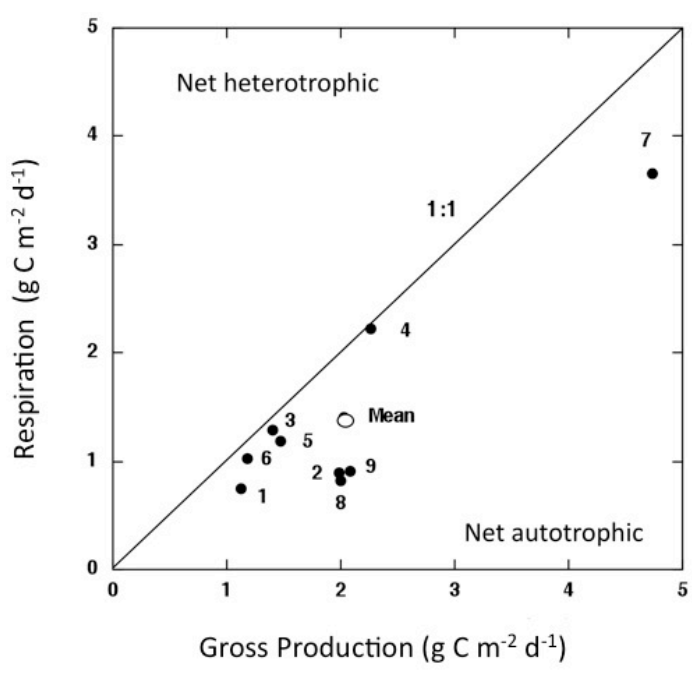

Fig. 3. The relationship between community respiration and gross production in the nine lagoon communities. The open symbol shows the mean value.

Gross primary production of the community ranged 4fold among the nine lagoon communities $\left(1.12-4.69 \mathrm{~g} \mathrm{C} \mathrm{m}^{-2}\right.$ $\mathrm{d}^{-1}$, Table 2 ), and exceeded community respiration in all of the sites by about $40 \%$ on average (Table 2 ), thereby yielding autotrophic communities supporting net production rates between 0.05 and $1.18 \mathrm{~g} \mathrm{C} \mathrm{m}^{-2} \mathrm{~d}^{-1}$ (Fig. 3, Table 2). Only one of the sites was in approximate metabolic balance, despite supporting high macrophyte biomass (Tables 1 and 2). Gross production and respiration rates were positively correlated ( $r=0.89, P=0.001$, Fig. 3). This is often observed (Duarte and Agustí 1998), because high plant biomass concurrently provides high gross production and respiration rates, and because high primary production also provides the organic substrate for extensive respiration by heterotrophic organisms.

The planktonic community was, in contrast, consistently net heterotrophic (average net production
$-0.14 \mathrm{~g} \mathrm{C} \mathrm{m}^{-2} \mathrm{~d}^{-1}$, Table 2) whereas the benthic community was net autotrophic at all stations (average net production $0.73 \mathrm{~g} \mathrm{C} \mathrm{m}^{-2} \mathrm{~d}^{-1}$, Table 2). Benthic gross production exceeded 40-fold that of phytoplankton (Table 2) in agreement with the low phytoplankton biomass, whereas benthic respiration exceeded planktonic respiration by only 7-fold (Table 2). Though phytoplankton biomass was low (Table 1), our estimates of pelagic production (Table 2) showed a close relationship to planktonic biomass $(r=0.80$, $P=0.02$ ). The ratio of gross pelagic production to phytoplankton biomass was about 2-3 $\mathrm{day}^{-1}$, indicating a fast turnover of the phytoplankton biomass. This indicates that phytoplankton growth was rapid, but that loss processes, likely grazing, maintain phytoplankton biomass low. This suggestion is consistent with the observation of dense (up to 80 ind. $\mathrm{L}^{-1}$ ) swarms of cladoceran zooplankton. Accepting a clearance rate of $1 \mathrm{ml}$ individual ${ }^{-1} \mathrm{~h}^{-1}$ (Lampert, 1987), this zooplankton density should be able to clear the water column twice a day, balancing the estimated phytoplankton growth rate.

The three-fold greater pelagic respiration rates relative to gross production suggests that heterotrophic organisms at this time of the year must rely on other carbon sources, most

likely organic carbon released from living and decomposing macrophytes incorporated by bacteria. Pelagic respiration exceeded production by, on average, $0.014 \mathrm{~g} \mathrm{C} \mathrm{m}^{-2} \mathrm{~d}^{-1}$ corresponding to only about $1 \%$ of the standing macrophyte biomass. This demand could be easily satisfied solely by extracellular organic carbon released from the plants. Turner (1978) found, for example, a leakage of 1-2\% of the Spartina biomass per day, similar to reported for a variety of submerged macrophytes by Søndergaard (1981). Both respiration and gross production remain sizeable at macrophyte biomasses approaching zero, indicating that sediment communities (e.g. benthic microalgae and heterotrophs) are significant contributors to community metabolism. 


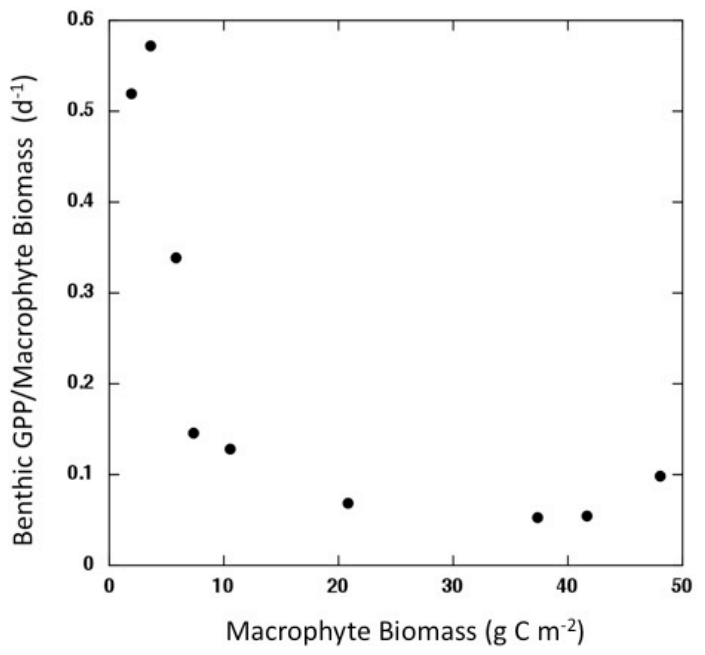

Fig. 4. The relationship between the ratio of daily benthic gross production to macrophyte biomass and macrophyte biomass in the nine lagoons.

The ratio of benthic gross production to macrophyte biomass was very high $\left(>0.12 \mathrm{~d}^{-1}\right)$ for macrophyte biomasses below $10 \mathrm{~g} \mathrm{C} \mathrm{m}^{-2}$ and declined to $0.05-0.10 \mathrm{~d}^{-1}$ for macrophyte biomasses above $20 \mathrm{~g} \mathrm{C} \mathrm{m}^{-2}$ (Fig. 4). Accounting for macrophyte respiration and some (but small) contribution of microphytobenthos at high macrophyte biomasses, the relative growth rates of macrophytes would be lower than $0.05-0.10 \mathrm{~d}^{-1}$, which are quite high for macrophyte communities. Relative growth rates at these levels can be expected for shallow lagoons during rapid spring macrophyte expansion (Nielsen and Sand-Jensen, 1991), whereas the large ratio of benthic gross production to macrophyte biomass at low macrophyte abundance is clearly affected by the production of epiphytes and microphytobenthos.

The fast growth rate and excess organic production postulated from oxygen metabolism would allow the macrophytes to develop extensive stands and produce flowers and seeds within the few months available before the marshes dry up. An analogous explosive development was observed in northern European lowland streams, which have suitable growth conditions in shallow and transparent waters at low discharge during mid-summer (Sand-Jensen et al., 1989).

The daily community metabolic balance depends on plant biomass as well as irradiance and temperature. Besides the strong diurnal oscillations, irradiance and temperature also varied among experimental days (Table 1), which may contribute to the weak dependence of net production on macrophyte biomass observed (Table 2). The relationship between net community production and irradiance in individual diurnal experiments showed a hysteresis pattern (Fig. 5), involving greater net community production rates in the morning compared to the afternoon for a given irradiance. The observed hysteresis is attributable to the strong dependence of

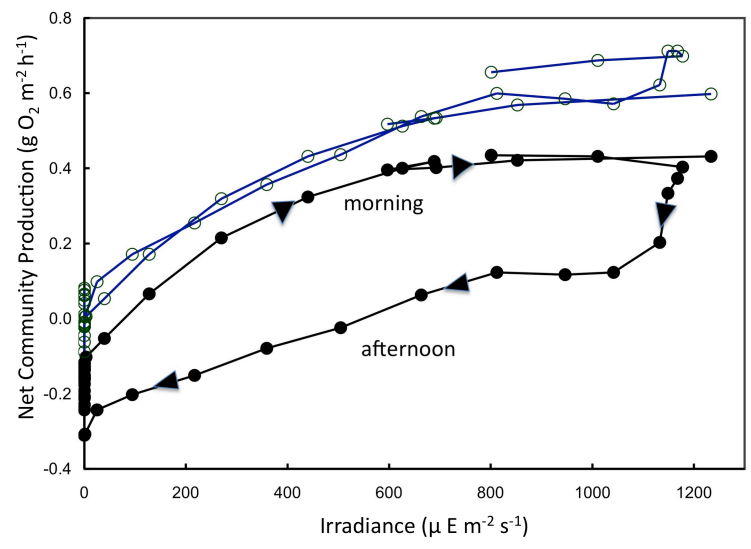

Fig. 5. Changes in hourly net community (benthic + pelagic) production (full circles) and gross production (open circles), calculated as net community production minus temperature-corrected respiration rates in Mari López Lagoon as a function of irradiance along the course of the day (i.e., the direction of the arrow in the full circles).

respiration rates on water temperature, leading to higher respiration rates in the warmer waters in the afternoon than in the cooler waters in the morning. During a sunny day the water temperature increased by 8 to $10^{\circ} \mathrm{C}$ and declined by a similar extent during the night (Table 1). We found, by fitting an Arhenius equation to the field data obtained during the night, respiration rates to increase about 3-fold for a $10^{\circ} \mathrm{C}$ temperature increase $\left(Q_{10}=2.9\right)$. Therefore, the irradiance needed for gross production to balance respiration was much higher in the afternoon than that in the morning.

Gross production showed the characteristic parabolic relationship to irradiance (Fig. 5). Analysis of the irradiancedependence of community metabolism, standardized to $20^{\circ} \mathrm{C}$, indicates a light compensation point for community metabolism ranging between 42 to $255 \mu \mathrm{E} \mathrm{m}^{-2} \mathrm{~s}^{-1}$ across the stations, with the communities becoming heterotrophic at lower irradiances (Table 3). These findings suggest that the communities may be often light limited, as the waters in the marsh oscillate between relatively high transparency and turbid conditions. The factors that lead to periods of high turbidity and light limitation include the input of high suspended particle loads during the flooding season in the winter; bioturbation due to trampling by wading birds and herbivore mammals, feeding by flamingos, present in thousands of birds in the lagoons, which produce turbidity plumes; and resuspension of very shallow sediments during windy days (Duarte et al., 1990). Our analyses also showed that the maximum community production ranged from 0.37 to $1.52 \mathrm{~g}$ $\mathrm{O}_{2} \mathrm{~m}^{-2} \mathrm{~h}^{-1}$ (Table 3).

Our results confirm, in agreement with results for shallow waters elsewhere (Kelly et al., 1983; Sand-Jensen et al., 1989) the dominant role of macrophytes as contributors to the metabolism and primary production of the open-water 
Table 3. The photosynthetic parameters: dark respiration rate $\left(R_{20}\right)$, initial slope $(\alpha)$, maximum net community production $\left(\mathrm{NCP}_{\text {max }}\right)$ and light compensation point $\left(I_{\mathrm{c}}\right)$ of the entire community (benthic and pelagic) in nine shallow Donana lagoons, based on $24 \mathrm{~h}$. measurements. All measurements normalised to $20^{\circ} \mathrm{C}$.

\begin{tabular}{lllll}
\hline Station & $R_{20}$ & $\alpha$ & $\mathrm{NCP}_{\max }$ & $I_{\mathrm{c}}$ \\
\hline & $\left(\mathrm{g} \mathrm{O}_{2} \mathrm{~m}^{-2} \mathrm{~h}^{-1}\right)$ & {$\left[\mathrm{g} \mathrm{O}_{2} \mathrm{~h}^{-1}\left(\mu \mathrm{E} \mathrm{s}^{-1}\right)\right]$} & $\left(\mathrm{g} \mathrm{O}_{2} \mathrm{~m}^{-2} \mathrm{~h}^{-1}\right)$ & $\left(\mu \mathrm{E} \mathrm{m}^{-2} \mathrm{~s}^{-1}\right)$ \\
1 & 0.18 & 0.0016 & 0.37 & 112 \\
2 & 0.12 & 0.0021 & 0.72 & 57 \\
3 & 0.23 & 0.0015 & 0.97 & 153 \\
4 & 0.17 & 0.0033 & 1.52 & 52 \\
5 & 0.17 & 0.0026 & 0.49 & 65 \\
6 & 0.09 & 0.0008 & 0.56 & 113 \\
7 & 0.51 & 0.0020 & - & 255 \\
8 & 0.21 & 0.0050 & 1.30 & 42 \\
9 & 0.15 & 0.0022 & 0.86 & 68 \\
Mean & 0.20 & 0.0023 & 0.85 & 102 \\
\hline
\end{tabular}

areas of the Doñana marsh. The macrophyte populations also show high gross production rates (max. $4.7 \mathrm{~g} \mathrm{C} \mathrm{m}^{-2} \mathrm{~d}^{-1}$ ) conducive to fast growth, flowering and seed formation of the plants during the short and suitable spring period before the lagoons dry up. Phytoplankton, although apparently fast growing, is heavily grazed and unable to meet the heterotrophic demands of the system, which appear to rely on macrophyte production for the supply of organic carbon. Because submerged macrophytes produce carbon in excess, the open-waters of the Doñana marsh are, as a whole, net autotrophic during the main growth season in spring, when macrophytes reach their peak development (Santamaria et al., 1996) and associated wild life is most abundant. The metabolic rates obtained for the marsh here are not as high as metabolic rates derived for other aquatic ecosystems in the Doñana National park, such as the hypertrophic Santa Ollala lagoon, supporting high gross primary production (average $2.9 \mathrm{~g} \mathrm{C} \mathrm{m}^{-2} \mathrm{~d}^{-1}$ ), but net heterotrophic communities (LópezArcilla et al., 2004), and were below the mean gross primary production for seagrass meadows of $3.1 \mathrm{~g} \mathrm{C} \mathrm{m}^{-2} \mathrm{~d}^{-1}$ (Duarte et al., 2010) but higher than most shallow lakes in the compilation in Table 3 by López-Arcilla et al. (2004).

The excess carbon produced by the ecosystem may meet multiple fates. Part of the excess carbon can be used to support bird requirements, particularly herbivorous waterfowl, many of which are targets for the conservation efforts in the Doñana National Park. A fraction of the excess carbon may accumulate in the sediments and support community metabolism in the following flooding phase, before macrophytes have developed. However, some of the excess organic carbon produced may simply accumulate in the sediments, contributing to the net sedimentation rates and the filling of the marsh. In fact, some of the organic carbon stored in the sediments over time does not represent a burial component, but rather a seed bank able of re-establishing the macrophyte communities after adverse conditions dissipate (Grillas et al., 1993). Lastly, a fraction of the excess organic carbon may be exported to be used in adjacent ecosystems with waters deep enough or turbid enough to exclude submerged macrophyte growth. Indeed, the Doñana marshes includes a mosaic of clear and turbid water systems that represent alternative stable states with different metabolic functions (Duarte et al., 1990; Santamaría et al., 1996; Gonzalez, 1999). Clearwater habitats are dominated by submerged macrophytes, which are shown here to support net autotrophic communities. In contrast, turbid or deeper waters are devoid of macrophytes, thereby dominated by a pelagic community, and likely receive irradiances below the light compensation for net community metabolism identified here. These turbid water parcels of the Doñana marsh are, therefore, likely to act as heterotrophic communities, requiring external carbon inputs. These heterotrophic parcels of the mosaic of the ecosystem within the Doñana marshes require external organic carbon inputs to meet their heterotrophic demands, which maybe derived from the excess carbon produced in the macrophyte-dominated clear water parcels of the mosaic.

The results presented identify a threshold irradiance for balanced metabolism estimated here at 42 and $255 \mu \mathrm{E} \mathrm{m}^{-2} \mathrm{~s}^{-1}$. Turbid or deep waters will have irradiances too low to support autotrophic communities, rendering the build up of macrophyte biomass unlikely. The development of macrophyte biomass and, eventually, autotrophic communities require, therefore, a minimum threshold irradiance. Both natural (e.g. resuspension, input of suspended sediments) and anthrophogenic actions (e.g. management options) that affect underwater light penetration may therefore lead to shifts from submerged macrophyte-dominated autotrophic communities to pelagic-dominated heterotrophic ones. Whereas actions to improve water clarity, therefore enhancing macrophyte biomass, may lead to autotrophic communities and increase waterfowl abundance, these actions may lead to the infilling of the shallow marsh, unless compensate by the co-existence with heterotrophic parcels of turbid waters, which will recycle some of the excess organic 
matter. A balance between autotrophic, clear water parcels and patches of turbid waters leading to a more balanced whole-system metabolism may help improve the conservation status of the ecosystem and maintain its characteristic high bird biomass and diversity.

In conclusion, the results presented here identify submerged macrophytes as a dominant source of organic carbon in the ecosystem of the Doñana marsh. The high primary production of the macrophyte communities confers resilience to the system (Scheffer et al., 1993; Scheffer, 2004) in that it helps maintain a storage organic carbon pool, which can be used to support heterotrophic demands during periods of organic matter shortage and to eventually re-establish the community from the seed bank. Management options at the Doñana marsh should strive at maintaining submerged macrophyte communities while preserving the mosaic structure of the ecosystem, including turbid water parcels that preclude an excess organic carbon accumulation in the system.

Acknowledgements. This work was funded by a grant from the Spanish Ministry of Education and Researc. OGH and KSJ were supported by funds allocated from the Danish Natural Science Research council, and PG by Tour du Valat Foundation. We thank Anne Grossman, and the park officials Antonio, Isidro, and Francisco Ibañez for their hospitality and assistance during field work, and La Gitana for consolation at all stages of this research.

Edited by: G. Herndl

\section{References}

Barnes, R. S. K., European estuaries and lagoons: a personal overview of problems and possibilities for conservation and management, Aquat. Conserv., 1, 79-87, 1991.

Bernués, M. S.: Limnologia de los ecosistemas acuáticos del Parque Nacional de Doñana. Ph.D. dissertation, Universidad Autonoma de Madrid, 242 pp., 1990.

Britton, R. H. and Crivelli, A. J.: Wetlands of southern Europe and North Africa: Mediterranean wetlands, edited by: Whigham D., Dykyjobá, D., Hejny, S., Wetlands of the world I: Kluwert, Boston, USA, 129-194, 1993.

Coleto, C.: Funciones hidrologicas y biogeoquímicas de las formciones palustres hipogénicas de los mantos eólicos de el Abalario-Doñana (Huelva), $\mathrm{PhD}$ thesis, Universidad Autonoma de Madrid ,2004.

Duarte, C. M. and Agustí, S.: The $\mathrm{CO}_{2}$ balance of unproductive aquatic ecosystems, Science, 281, 234-236, 1998.

Duarte, C. M. and Prarie, Y. T.: Prevalence of heterotrophy and atmospheric $\mathrm{CO}_{2}$ emissions from aquatic ecoystems, Ecosystems 8, 862-870, 2005.

Duarte, C. M., Montes, C., Augustí, S., Martino, P., Bernués, M., and Kalff, J.: Biomassa de macrófitos acuáticos en la marisma del Parque National de Doñana (SW España): importancia y factores ambientales que controlan su distribución, Limnética, 6, 1-12, 1990.

Duarte, C. M., Marbà, N., Gacia, E., Fourqurean, J. W., Beggins, J., Barrón, C., and Apostolaki, E. T.: Seagrass community metabolism: Assessing the carbon sink capacity of seagrass meadows, Global Biogeochem. Cy., 24, GB4032, doi:10.1029/2010GB003793, 2010.

Espinar, J. L., Garcia, L. V., Garcia Murillo, P., and Toja, J.: Submerged macrophyte zonation in a Mediterranean salt marsh: a facilitation effect from established helophytes?, J. Veg. Sci., 4, 417-424, 2002.

Hollis, G. E. and Jones, T. A.: Europe and the Mediterranean Basin, edited by: Finlayson, M. and Moser, M., Wetlands, IWRB, Facts on File, Oxford, 27-56, 1991.

Garcia, L. V., Marañon, T., Moreno, A., and Clemente, L.: Aboveground biomass and species richness in a Mediterranean salt marsh, J. Veg. Sci., 4, 417-424, 1993.

Garcia Murillo, P., Bernues, M., and Montes, C.: Los macrófitos acuáticos del Parque Nacional de Doñana (SW España), Aspectos florísticos Actas del VI Congreso Español de Limnología Madrid, Spain, 261-267, 1993.

Gonzalez, M. D.: Ecología del banco de semillas de hidrofítas de la marisma del Parque Nacional de Doñana, PhD thesis, Universidad Autonoma de Madrid, Spain, 1999.

Grillas, P.: Distribution of submerged macrophytes in the Camargue in relation to environmental factors, J. Veg. Sci., 1, 339-402, 1990.

Grillas, P. and Roché, J.: Vegetation of temporary marshes, Ecology and management. Conservation of Mediterranean Wetlands, MedWet no. 8, Tour du Valat, 1997.

Grillas, P., Garcia-Murillo, P., Geertz-Hansen, O., Marbá, N., Montes, C., Duarte, C. M., Tan Ham, L., and Grossmann, A. Submerged macrophyte seed bank in a Mediterranean temporary marsh: abundance and relationship with established vegetation, Oecologia, 94, 1-6, 1993.

Grillas, P., Gauthier, P., Yavercovski, N., and Perennou, C.: Mediterranean Temporary Pools, Vol. 1, Issues relating to conservation, functioning and management, Tour du Valat, 2004.

Gromiec, M. J.: Reaeration, Mathematical submodels in water quality systems, edited by: Jorgensen, S. E. and Gromiec, M., Elsevier, 33-64, 1989.

Jespersen, A. M. and Christoffersen, K.: Measurements of chlorophyll-a from phytoplankton using ethanol as extraction solvent, Arch. Hydrobiol., 109, 445-454, 1987.

Keddy, P. A.: Wetland Ecology. Princiiples and conservation, Cambridge Studies in Ecology, Cambridge University Press, 2000.

Kelly, M. G., Thyssen, N., and Moeslund, B.: Light and the annual variation of oxygen- and carbon-based measurements of productivity in a macrophyte-dominated river, Limnol. Oceanogr., 28, 503-515, 1983.

Lampert, W.: Feeding and nutrition in Daphnia, Mem. Ist. Ital. Idrobio, 145, 143-192, 1987.

Langdon, C.: On the causes of interspecific differences in the growth-irradiance relationship for phytoplankton, II, A general review, J. Plankton Res., 10, 1291-1312, 1988.

López-Archilla, A. I., Mollá, S., Coleto, M. C., Guerrero, M. C., and Montes, C., Ecosystem metabolism in a Mediterranean shallow lake (Laguna Sta Olalla, Doñana National Park, SW Spain), Wetlands, 24, 848-858, 2004.

Lorenzen, C. J.: Carbon/Chlorophyll relationships in an upwelling area, Limnol. Oceanogr., 13, 202-204, 1968.

Nielsen, S. L. and Sand-Jensen, K.: Variation in growth rates of submerged rooted macrophytes, Aquat. Bot., 39, 109-120, 1991.

Odum, E. P. and Barret, G.: Fundamentals of Ecology 5th 
ed.Thomson Brooks/Cole, Philadelphia, USA, 2005.

Odum, H. T. and Hoskin, C. M.: Comparative studies on the metabolism of marine waters, Publ. Inst. Mar. Sci. Univ. Texas, USA, 5, 16-46, 1958.

Odum, H. T. and Wilson, R. F.: Further studies on reaeration and metabolism of Texas bays, 1958-1960, Publ. Inst. Mar. Sci. Univ. Texas, 8, 23-55, 1962.

Rivas Martinez, S., Costa, M., Castroviejo, S., and Valdes, B.: Vegetación de Doñana (Huelva), Lazaroa, 2, 5-190, 1980.

Sand-Jensen, K., Jeppesen, E., Nielsen, K., van der Bijl, L., Hjermind, A. L., Nielsen, L. W., and Iversen, T. M.: Growth of macrophytes and ecosystem consequences in a lowland Danish stream, Freshwater Biol., 22, 15-32, 1989.

Santamaria, L., Montes, C., and Hootsmans, M. J.: Influence of environmental parameters on the biomass development of Ruppia drepanensis populations in Doñana National Park: the importance of conditions affecting the underwater Light climate, Int. J. Salt Lake Res., 5, 157-180, 1996.

Scheffer, M.: Ecology of shallow lakes, Kluwer Academic Publish, Dordrecht, The Netherlands, 357 pp., 2004.
Scheffer, M., Hosper, S. H., Meijer, M. L., Moss, B., and Jeppesen, E.: Alternative equilibria in shallow lakes, Trends Ecol. Evol., 8, 275-279, 1993.

Sondergaard, M.: Kinetics of extracellular release of 14C labeled organic carbon by submerged macrophytes, Oikos, 36, 331-344, 1981.

Skinner, J. and Zalewski, S.: Function and values of Mediterranean wetlands, Conservation of Mediterranean wetlands, MedWet, no. 2, Tour du Valat, 1995.

Turner, R. E.: Community plankton respiration in a salt marsh estuary and the importance of macrophytic leachates, Limnol. Oceanogr., 23, 442-451, 1978.

Van Es, F. B.: Community metabolism of intertidal flats in the EmsDollard Estuary, Mar. Biol. 66, 95-108, 1982.

Van Vierssen, W.: The ecology of communities dominated by Zannichellia taxa in Western Europe. II. Distribution, synecology and productivity aspects in relation to environmental factors, Aquat. Bot., 13, 385-483, 1982. 